\title{
A cadaveric study of the third head of biceps brachii in south Indian population
}

\author{
P R Prefulla ${ }^{1}$ B J Bhuvaneswari2*
}

1,2Assistant Professor, Institute of Anatomy, M adras M edical College, Chennai, PIN- 600003, INDIA.

Email: prefullanambiar@gmail.com,bhuvanaranjith04@gmail.com

\begin{abstract}
Biceps brachii is a two headed muscle in the flexor compartment of arm. Third head of Biceps brachii has been reported by various authors worldwide. The third head of Biceps brachii has significant functional and clinical implications. The present study was carried out in 100 upper limb specimens from 50 embalmed adult human cadavers at the Institute of Anatomy, Madras Medical College, Chennai, India. Presence of third head of Biceps brachii, its origin, insertion and nerve supply were studied in detail. The findings would be valuable to Anatomists, Radiologists, Orthopaedicians and Plastic surgeons.
\end{abstract}

Key Word: Biceps brachii, Third head, Musculocutaneous nerve, Intramuscular compression, Biceps brachii flap, Fracture humerus.

*Address for Correspondence:

Dr. B J Bhuvaneswari, Assistant Professor, Institute of Anatomy, Madras Medical College, Chennai, PIN- 600003, INDIA.

Email: bhuvanaranjith04@gmail.com

Received Date: 27/01/2019 Revised Date: 17/02/2019 Accepted Date: 20/03/2019

DOI: https://doi.org/10.26611/10011011

\begin{tabular}{|l|l|}
\hline \multicolumn{2}{|c|}{ Access this article online } \\
\hline Quick Response Code: & Website: \\
\hline & www.medpulse.in \\
\hline
\end{tabular}

\section{INTRODUCTION}

Biceps brachii is a large fusiform muscle in the flexor compartment of arm. The muscle arises by two heads, as implied by its name. The tendon of long head is attached to the supraglenoid tubercle of scapula and lies intracapsular in the shoulder joint. The short head arises as a thick flattened tendon from the tip of coracoid process of scapula. The tendinous origin of each head expands into fleshy bellies. The two bellies lie side by side, loosely connected by areolar tissue, but do not merge to form a single flattened tendon until just above the elbow joint. The tendon of Biceps brachii gets inserted to the posterior part of radial tuberosity ${ }^{8}$. Bicipital aponeurosis spreads downwards and medially from the anteromedial aspect of the tendon and partly in continuity with the fleshy fibres of the muscle. It joins the deep fascia of forearm and is inserted into the subcutaneous border of the upper end of ulna ${ }^{11}$. Each head of Biceps brachii receives a twig from Musculocutaneous nerve. These twigs are composed of fibres derived from the ventral rami of $5^{\text {th }}$ and $6^{\text {th }}$ cervical spinal nerves ${ }^{19}$. Biceps brachii is a three-joint musclecrossing the shoulder, elbow and superior radio-ulnar joints ${ }^{11}$. It is a powerful supinator. It flexes the elbow, most effectively with forearm supinated and also acts as a weak flexor of the shoulder joint ${ }^{8}$. A not uncommon variation of the Biceps brachii muscle is the presence of a third head ${ }^{19}$. The origin of third head of Biceps brachii is variable. It may be from the shaft of humerus near the insertion of coracobrachialis $^{6}$, or fascia over brachialis ${ }^{7}$, intertubercular sulcus ${ }^{3}$, anterior limb of $\mathrm{V}$ shaped insertion of deltoid ${ }^{5}$. The presence of a third or humeral head might increase the dynamics of Biceps brachii, as otherwise the muscle is devoid of any humeral attachment. This may cause unusual bone segment displacement in fracture of humerus. The incidence of third head of Biceps Brachii has been reported by several authors worldwide. The present study was carried out to explore the third head of Biceps brachii in South Indian population.

\section{MATERIALS AND METHODS}

The study was carried out in 100 upper limb specimens from 50 embalmed adult human cadavers allotted for 
routine undergraduate dissection at the Institute of Anatomy, Madras Medical College, Chennai, India. Careful dissection was done to study the Biceps brachii muscle from proximal to distal attachments. Presence of third head of Biceps brachii, its origin, insertion and nerve supply were analysed in detail.

\section{OBSERVATIONS AND RESULTS}

Out of 100 upper limb specimens, 11 showed the presence of third head of Biceps brachii (Fig.1). It was noted bilaterally in one cadaver. Out of the remaining 49 cadavers, third head was noted on the right side in 5 upper limbs and left side in 4 upper limbs.

Table 1: Cadaveric incidence of third head of Biceps brachii

$\frac{\text { Unilateral }}{\text { Right Left }}$ Bilateral

$$
\begin{array}{lll}
5 & 4 & 1
\end{array}
$$

In 10 out of 11 specimens, the third head of Biceps brachii took origin from the anteromedial surface of shaft of humerus in the area between insertion of Coracobrachialis and origin of Brachialis. In 1 upper limb, the origin was from the proximal part of fascia over brachialis.

Table 2: Site of origin of third head of Biceps brachii

\begin{tabular}{cc}
\hline Shaft of humerus & Fascia over brachialis \\
\hline 10 & 1
\end{tabular}

In all cases, the third head of Biceps brachii merged with the other two heads (Fig.1) and inserted through the tendon of biceps brachii and bicipital aponeurosis. The third head was innervated by a twig from Musculocutaneous nerve. Presence of third head was not associated with any variation in the long and short heads of Biceps brachii. In 3 upper limbs (3\%), Musculocutaneous nerve was found to course between third head and the other 2 heads. (Fig.2)

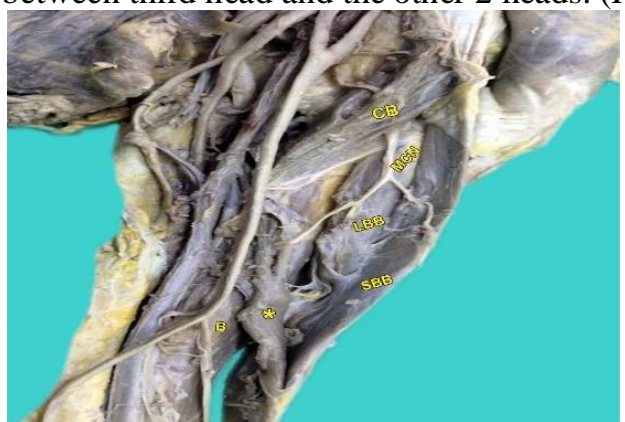

Figure 1: Left fro nt of arm showing Long head of Biceps brachii (LBB), Short head of Biceps brachii (SBB) and Third head of Biceps brachii $(*)$.

Note the origin of Third head of Biceps brachii from shaft of humerus, from the area between insertion of Coracobrachialis (CB) and origin of Brachialis (B). Note the nerve supply to all the three heads of Biceps brachii from Musculocutaneous nerve (MCN).

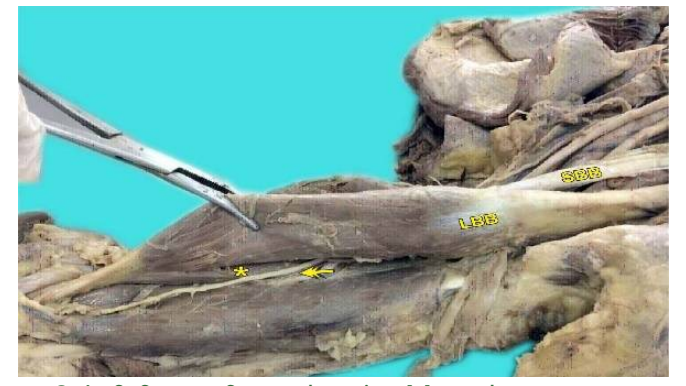

Figu re 2: Left front of arm showing M usculocutaneous nerve between Third head of Biceps brachii $(*)$ and the other two heads. LBB- Long head of Biceps brachii, SBB- Short head of Biceps brachii.

\section{DISCUSSION}

In the present study, the incidence of third head of Biceps brachii was $11 \%$. This correlates to the reports of Amar Jayanthi et al $(10.8 \%)^{2}$ and Ramakrishna Avadhani et al $(16.67 \%)^{12}$ In 10 out of the 11 upper limbs in which third head of Biceps brachii was present, it took origin from shaft of humerus. The site of origin was the area between insertion of Coracobrachialis and origin of Brachialis, coinciding with the findings of Prabhjot Cheema et $a l^{10}$, Abdullah $\mathrm{G}^{1}$, PP Poudel et $a l^{9}$, Renu Gupta et $a l^{14}$ and Renata Pacholczak et $a l^{13}$. Origin from fascia over Brachialis, which was $1 \%$ in the present study, has also been reported by Vinnakota Sunitha et $a l^{18}$ and S. Soni et $a l^{16}$. The other reported areas of origin of the third head are intertubercular groove of humerus ${ }^{3}$ and anterior limb of $\mathrm{V}$ shaped insertion of Deltoid ${ }^{5}$. These were not found in the present study. In the present study, unilateral incidence of third head of Biceps brachii(10\%) was found to be much higher than bilateral incidence $(1 \%)$. This is similar to the findings of Amar Jayanthi et $a l^{2}$, Prabhjot Cheema et a $l^{10}$ and Eti Sthapak et $a l^{4}$. The incidence was found to be slightly higher on the right side $(6 \%)$ than on the left side $(5 \%)$. This is similar to the findings of Eti Sthapak et $a l^{4}$. In all cases, the third head of Biceps brachii joined with the other 2 heads and inserted through Biceps tendon and bicipital aponeurosis. This harmonizes with the findings of B.O Donmez et $a l^{3}$, Satheesha Nayak et $a l^{15}$ and Eti Sthapak et $\mathrm{l}^{4}$. Nerve supply of the third head was by a twig from Musculocutaneous nerve, in all cases. This conforms to Prabhjot Cheema et $a l^{10}$, Vinnakota Sunitha et $a l^{18}$, Hitendra Kumar ${ }^{5}$ et $a l$ and B.O Donmez et $a l^{3}$. Musculocutaneous nerve was found to course between the third head and the other two heads in $3 \%$. This tallies with the findings of M. Mujahid Ansari et $a l^{7}$ and Satheesha Nayak et $a l^{15}$. This intramuscular course is a potential site for compression of musculocutaneous nerve. 


\section{CONCLUSION}

Knowledge of the incidence of third head of Biceps brachii and its morphology is of importance in traumatology. The intramuscular course of Musculocutaneous nerve gains importance in hypertrophied Biceps brachii muscle as in professional body builders and weight lifters. Biceps brachii muscle flaps are used in plastic and reconstructive surgeries for axillary wound coverage. An additional head would be of added value in such cases. Hence the findings of the present study would be valuable to Anatomists, Radiologists, Orthopaedicians and Plastic surgeons.

\section{REFERENCES}

1. Abdullah G Al- Kushi: Anatomical study of the third head of biceps brachii muscle and its innervation by median nerve in human dissection: Journal of Clinical Medicine and Research. 2013 June; 5(4): 47-52

2. Amar Jayanthi. A, Elezy. M. A: Study of variations in the Origin of Biceps brachii muscle in Kerala: International Journal of Scientific and Research Publications. 2012 August; 2(8): 1-3

3. Baris Ozgur Donmez, Bahadur Murat Demirel, Umut Ozsoy, Arzu Utuk, Levent Sarikcioglu: Variation of the supernumerary head of the biceps brachii muscle, 2 case reports and literature review: International Journal of Experimental and Clinical Anatomy. 2010 January: 63-66

4. Eti Sthapak, Navbir Pasricha, Mohammed shakil Siddiqui: Study of variations in the origin of biceps brachii with special thrust on its innervations: International Journal of Anatomy and Research. 2016; 4(1): 1994-1997

5. Hitendra Kumar, Srijit Das, Gayatri Rath: An anatomical insight into the third head of Biceps brachii muscle: Bratisl Lek Listy. 2008; 109(2):76-78

6. J.C. Brash, E.B. Jamieson: Cunningham's Textbook of Anatomy. $7^{\text {th }}$ edition: 462

7. M. Mujahid Ansari, U.K.Gupta, M. Laique Ahmed, S. Fayyaz Ali: Third head of Biceps brachii with anatomical consideration and clinical implication- A case report: Journal of Evolution of Medical and Dental Sciences. 2013 February; 2(6)

8. Peter. L. Williams: Gray's Anatomy. $38^{\text {th }}$ edition: 843

9. Poudel P. P, Bhattarai C: Study on the supernumerary heads of biceps brachii muscle in Nepalese: Nepal Medical College Journal. 2009; 11(2): 96-98

10. Prabhjot Cheema, Rajan Singla: Low Incidence of the Third Head of the Biceps Brachii in the North Indian Population: Journal of Clinical and Diagnostic Research. 2011; 5(7): 1323-1326

11. R.M.H. McMinn: Last's Anatomy Regional and Applied. $9^{\text {th }}$ edition: 160

12. Ramakrishna Avadhani, K. Kalyan Chakravarthi: A study on morphology of the biceps brachii muscle: Nitte University Journal of Health Sciences. 2012 September; 2(3): $2-5$

13. Reneta Pacholczak, Wieslawa Klimek- Piotrowska, Jerry A Walocha: Absence of the musculocutaneous nerve associated with a supernumerary head of biceps brachii: a case report: Surg Radiol Anat; 2011 January.

14. Renu Gupta, S. B. Ray: Anomalous third head of Biceps brachii and Pronator teres in single cadaver: JIMSA. 2013 October- December; 26(4): 224-225

15. Satheesha Nayak, Vijay Paul Samuel, Nagabhooshana Somayaji: Concurrent variations of median nerve, musculocutaneous nerve and biceps brachii muscle: Neuroanatomy. 2006; 5:30-32

16. Soni S, Ghulyani T, Saxena A, Saraswat NK: The term 'biceps brachii': a misnomer?: OA Case Reports. 2013 July; 2(5): 48

17. Todd M. Willcox, Sumeet. S. Teotia, Anthony A. Smith, Jeffery M. Rawlings: The Biceps brachii muscle flap for axillary wound coverage: Plastic and Reconstructive Surgery. 2002 October; 110(3):822-826

18. Vinnakota Sunitha, Bhattam Narasingarao: Bilateral Three Headed Biceps Brachii- A Case Report: People's Journal of Scientific Research. 2011 July; 4(2): 53-54

19. W. Henry Hollinshead: Anatomy for Surgeons. Vol 3, $2^{\text {nd }}$ edition: 360-363

Source of Support: None Declared
Conflict of Interest: None Declared

